\title{
Kollektiivisen trauman julkinen työstäminen: Tampere 1918
}

\begin{abstract}
Monissa maissa on käynnistynyt 1990-luvulta lähtien yhteiskunnallisia kriisejä ja kollektiivisia traumoja työstäviä prosesseja. Artikkeli tarkastelee mikä julkisuuden ja medioiden rooli voisi olla kollektiivisen trauman työstämisessä. Artikkeli esittelee kansainvälistä keskustelua kollektiivisten traumojen työstämisestä ja tarkastelee erityisesti Suomen vuoden 1918 sisällissodan työstämistä vuonna 2008 Tampereella. Museokeskus Vapriikin näyttelyssä ja keväällä 2008 Tampereella järjestetyssä katudraamassa käytiin läpi Tampereen taistelujen viimeisiä vaiheita niiden tapahtumapaikalla. Näihin tapahtumiin on liittynyt myös verkon käyttö: aineistojen esittely, muistojen kerääminen ja keskustelu. Artikkelissa todetaan, että kollektiivisten traumojen työstäminen on monipolvinen ja mutkikas prosessi eikä poppakonsti yhteiskunnallisten ongelmien ratkaisemiseksi. Siitä huolimatta vuoden 1918 tapahtumien julkisessa muistelussa vuonna 2008 on useita piirteitä, jotka näyttävät toimivilta traumateorian näkökulmasta ja pyrkivät stereotypioiden, viholliskuvien ja siirtotaakkojen purkamiseen. Julkisuudella on ollut näissä prosesseissa monia rooleja.
\end{abstract}

AVAINSANAT: kulttuurinen trauma, julkisuus, sisällissota, Tampere, 1918

V oiko kokonainen yhteiskunta työstää traumojaan samalla tavalla kuin yksittäinen ihminen? Tähän kysymykseen on annettu vaihtelevia vastauksia eri puolilla maailmaa 1970-luvulta lähtien. Tässä tarkastelen kollektiivisen trauman purkamista ennen muuta julkisuuden kannalta: mikä julkisuuden ja eri medioiden rooli voi olla kollektiivisen trauman työstäjänä.

Käytän esimerkkinä Suomen vuoden 1918 sisällissodan julkista muistamista Tampereella vuoden 2008 aikana. Suomessa vuoden 1918 tapahtumat jakoivat kansalaiset dramaattisella ja väkivaltaisella tavalla kahteen toisiaan vastaan taistelevaan osapuoleen. Sodan jälkeen myös sen käsittely julkisena kysymyksenä sisälsi monia kulttuuriselle traumalle tyypillisiä piirteitä.

Sisällissodasta tuli kuluneeksi 90 vuotta vuonna 2008 ja vuoden aikana järjestettiin lukuisia tapahtumia, luentosarjoja, filminäytöksiä, näyttelyitä ja keskustelutilaisuuksia vuoden 1918 tapahtumista. Käsittelen tässä artikkelissa erityisesti vuoden 1918 muistonäyttelyä Tampereella Vapriikissa' ja Sovinnon päivää, Tampereen taiste- 
lujen tapahtumapaikoilla järjestettyä katudraamaa. Pohdin niiden valossa, mikä voi olla julkisuuden rooli kollektiivisen trauman työstämisessä.

Tapaustutkimus tarjoaa monia kiinnostavia esimerkkejä siitä, miten traumaa voidaan työstää julkisesti. Perustavoitteena oli pyrkiä eroon sodan jyrkistä, toisiaan vainoavista identiteeteistä ja stereotyyppisistä viholliskuvista ja me-fantasioista. Löytämällä joustavamman suhtautumisen menneisyyteen, ihmiset voivat suhtautua joustavammin ja sallivammin myös nykyhetkeen.

Julkisuus oli tässä Tampereella tärkeässä roolissa. Erityisesti nousivat esiin menneisyyden dokumenttien käyttö sekä toisaalta menneisyyden dramatisointi: julkiset performanssit, joiden avulla voidaan eläytyä vuoden 1918 tapahtumiin. Lisäksi julkisen prosessin monimuotoisuus oli kiinnostavaa. Kyse ei ollut vain suuresta valtajulkisuudesta, vaan vuoden 1918 muistelemisessa käytettiin monia muita julkisen muistamisen keinoja, kuten näyttelyä, katudraamaa, muisteluja, vieraskirjoja, blogeja, verkkokeskusteluja ja keskustelutilaisuuksia.

Lopuksi tuon esiin myös sitä, että kollektiivisen trauman työstämisellä on rajansa: se ei ole poppakonsti poliittisten vaikeiden kysymysten ratkaisemiseen ja ohittamiseen. Trauman työstäminen vaatii myös useimmiten ajallista etäisyyttä. Tampereen trauman työstäminen oli mahdollista siksi, että yhteiskunnassa aikuistui sukupolvi, jolla ei enää ollut suoraa yhteyttä sotatapahtumiin edes vanhempiensa muistojen kautta.

Aina on olemassa myös se mahdollisuus, että trauman purkamista käytetään poliittisesti väärin mitätöimään menneisyyden vääryyksiä ja epäoikeudenmukaisuuksia. Historiankirjoituksella, oikeudenkäynneillä ja politiikalla on myös paikkansa eikä trauman purkamista pidä ymmärtää niiden korvikkeena.

\section{Kollektiivisten traumojen työstäminen}

Kollektiivisten traumojen purkaminen on saanut monia muotoja. Kirjo ulottuu kansanmurhien ja sisällissotien selvittelystä autoritaaristen valtioiden arkistojen avautumiseen ja sotasyyllisyysoikeudenkäynteihin (Barkan 2000; Hydén 2000; Carey 2003).

Ehkä tunnetuimpia esimerkkejä ovat olleet totuuskomissiot, joita on käytetty kehittyvissä maissa osana demokratisoitumisprosessia (Posel 2008, 199). Nelson Mandelan aloitteesta 1995 käynnistynyt Etelä-Afrikan totuus- ja sovittelukomissio (TRC) on kuuluisin esimerkki, ja samaan tapaan totuuskomissioita on toiminut muun muassa El Salvadorissa, Argentiinassa, Chilessä, Guatemalassa, Haitissa, Kuubassa, Ruandassa, Sierra Leonessa; Liberiassa ja Itä-Timorissa (esim. Hayner 2002; Stahn 2001; Sesay 2007).

Traumojen työstäminen ei ole kuitenkaan mitenkään yksiselitteinen ja ongelmaton kysymys. Usein on kyse yhteiskuntien arimmista poliittisista kysymyksistä, joihin liittyy väkivaltaa ja epäoikeudenmukaisuutta. Olisi outoa, että nämä kysymykset voitaisiin ratkaista helposti kollektiiviseen terapiaan erikoistuneiden terapeuttien vastaanotolla.

Traumojen työstäminen onkin herättänyt paljon myös kritiikkiä siitä, että sovittelusta on tullut kansainvälinen muoti, "teollisuudenala" (Moon 2008). Tulokset ovat usein olleet vaatimattomia erityisesti niissä tapauksissa, joissa trauman syyt 
kuten korruptoituneisuus, syrjintä tai köyhyys, ovat edelleen voimissaan (Sesay 2007, 46-53).

On myös kysytty, pitäisikö keskittyä uuden elämän rakentamiseen sen sijaan, että yritetään herättää intohimoja, jotka ovat johtaneet tuhoon ja väkivaltaan (Ignatieff 1999). Useimmissa työstämisprosesseissa on ollut mukana ristiriitainen jännite: uhrit ovat halunneet unohtaa kärsimyksensä, ja toisaalta heitä on painanut tarve muistaa ja saada hyvitystä (Hayner 2002).

Historian tutkijat ovat olleet erityisen epäileväisiä. Sovitteluprosessit ovat usein päällekkäisiä historiankirjoituksen kanssa (Torpey 2003) ja trauman purkaminen on ongelmallista, jos sillä yritetään ohittaa historiankirjoituksen vaivalloisuus (Attwood ym. 2008, 3). Vaikka historiantutkimuksella on ollut välillä merkittävä rooli traumojen työstämisessä (Hentilä 2005), niin molempia onkin voitava pitää erillisinä prosesseina, joilla on omia erityisiä tavoitteitaan.

Tässä keskityn pohtimaan erityisesti julkisuuden roolia kollektiivisten traumojen työstäjänä. Aihetta on pohdittu toistaiseksi varsin vähän mediatutkimuksessa. Joitakin esimerkkejä kuitenkin on. Mediatutkimuksessa on pohdittu journalismin roolia Gazassa kollektiivisen trauman purkamisen näkökulmasta (TeneboimWeinblatt 2008). Myös mediatutkimuksen ja rauhantutkimuksen risteyksessä on perinteisesti syntynyt tutkimusta (Galtung \& Ruge 1965), joka korostaa viholliskuvien purkamista.

Ehkä kiinnostavimmin julkisuuden merkitystä on kuitenkin pohdittu erityisesti ns. kulttuurisen trauman teoriassa (Eyerman 2001; Alexander 2003; 2006; Alexander ym. 2004; Alexander ym. 2006; Giesen 2004a; Giesen 2004b; ks. myös Adelaid-Tart 2006) sekä Public Culture -lehden ympärille ryhmittyneessä julkisuuden tutkimuksessa, joka on nojannut muun muassa Charles Taylorin (1994) ja Arjun Appadurain (2006) ajatuksille (Attwood ym. 2008). Nojaankin seuraavassa erityisesti näihin tutkimussuuntiin.

\section{Trauman purkamisesta: valistus ja psykoanalyysi}

Jeffrey Alexanderin $(2004,1)$ määritelmän mukaan kulttuurinen trauma syntyy, kun "yhteisön jäsenet kohtaavat kauhean tapahtuman, joka jättää pysyvät jäljet heidän ryhmätietoisuuteensa muokaten sen muistoja ja ryhmän identiteettiä perustavalla ja peruuttamattomalla tavalla".

Kollektiiviseen traumaan liittyy oleellisena osana sen julkinen tuottaminen. Kollektiivinen trauma syntyy ja tuotetaan usein julkisuudessa itse tapahtumien jälkeen: julkiset tulkinnat muokkaavat tapahtuman, joka merkitsee kollektiivisten identiteettien kriisiä. (Eyerman 2001, 2-3.)

Kollektiivista traumojen purkamista on ymmärretty pääasiassa kahdesta lähtökohdasta: valistuksen ja psykoanalyysin (Alexander 2004, 3-8). Valistuksen näkökulmasta ajatuksena on, että menneisyyttä voidaan tarkastella järkiperäisesti niin, että siitä voidaan muodostaa järkevä näkemys, jota voidaan sovittaa materiaalisesti tai anteeksipyynnöin (Barkan 2000, 314-317).

Psykoanalyyttinen traumateoria taas painottaa vaiettujen kokemusten muistamista (Smelser 2004, 34-59). Vaikeneminen voi tuottaa jäykkää, omista tunteista etäännytettyä, toistamispakkoista tai aggressiivista käyttäytymistä, ja tavoit- 
teena on purkaa jäykistyneitä muistoja ja ajattelutapoja. Ron Eyermanin (2001, 4) mukaan trauman työstäminen on prosessi, jossa vaietut ja vaihtoehtoiset kokemukset tuodaan esiin ja tapahtumille annetaan uusia merkityksiä, jotka tekevät mahdolliseksi sovinnon menneisyyden ja nykyhetken välillä.

Erityisesti tavoitteena on mustavalkoisten me- ja he-fantasioiden ja stereotyyppisten viholliskuvien purkaminen. Ne ovat "suojelevia fiktioita", psyykkinen fasadi, joka lukitsee tien menneisyyteen ja muistiin (Rose 1996, 5). Juuri sisällissotiin liittyy usein toisiaan vainoavia identiteettejä, freudilaista pienten erojen narsismia, joka vaatii toiseksi määriteltyjen poistamista tai tuhoamista (Appadurai 2006, 51). On paradoksaalista, että veljekset voivat vihata toisiaan paljon intensiivisemmin kuin vieraat (Ignatieff 1999, 47).

Käytännössä menneisyyden traumaattisia tapahtumia on työstetty ja purettu julkisuudessa monin tavoin. Näitä julkisen käsittelyn muotoja ovat olleet esimerkiksi vaietun näkökulman tunnistaminen, syyllisyyden julkiset tunnustukset, julkiset anteeksipyynnöt, julkiset muistomerkit ja muiston kunnioittaminen, julkinen sovittelu sekä tarinoiden jakaminen (story sharing).

Vaiettujen näkökulman tunnistaminen tarkoittaa prosesseja, joiden tarkoituksena on tuoda vaietut äänet julkisuuteen. Taylor $(1994,26)$ puhuu "historiallisesta haavasta", joka syntyy kun jokin ihmisryhmä ei saa ääntään kuuluviin julkisuudessa, tai tunnistetaan julkisuudessa tavoilla, jotka eivät vastaa sen omaa itseymmärrystä tai ovat vahingollisia.

Tunnistaminen on yleensä koskenut kokonaisen kansanosan ja etnisen ryhmän, esimerkiksi alkuperäiskansan tai orjuuden tekemistä julkiseksi. Myös väkivaltaa ja kansanmurhia on tuotu julkisuuteen. (Attwood ym. 2008, 1-2; Barkan 2000.) Prosesseihin on liittynyt myös dokumentaariaineistojen tulo päivänvaloon ja kulttuurinen muistaminen: kirjallisuus, elokuvat ja näytelmät.

Julkiset tunnustamiset ja anteeksipyynnöt ovat liittyneet prosesseihin, joissa tekijät ovat julkisesti tunnustaneet osuutensa menneisyyden tapahtumiin. Keskustelu tunnustamisesta käytiin esimerkiksi natsi-Saksan perintöä selviteltäessä, joskin varsinaisia julkisia tunnustamisia nähtiin suhteellisen vähän (Giesen 2004a). Myös DDR:n purkautuessa vanhan vallan edustajat osin tunnustivat oman osuutensa arkistojen avautuessa (Ignatieff 1999, 180-181).

Julkiset tunnustukset ovat olleet tärkeässä roolissa myös monien totuuskomissioiden työssä. El Salvadorin komissio oli ensimmäinen, jossa myös väärintekijät nimettiin julkisesti (Stahn 2001, 954-955). Etelä-Afrikan totuuskomissio puolestaan lupasi armahduksen totuuden kertomisesta. Julkisista tunnustuksista kehittyi rituaaleja, joissa yhdistyivät kristilliset, juridiset ja terapeuttiset elementit. Tunnustajat saivat komissiolta synninpäästön. Symbolisesti eri kansanosia edustavat tunnustukset otti vastaan arkkipiispa Desmond Tutu ja niitä valvoi oikeudenkäyntien tapaan erityinen komissio. Tavoite oli myös terapeuttinen. Ajatuksena oli, että tunnustamalla menneisyytensä teot tunnustaja pääsi niistä myös itse vapaaksi. (Posel 2008, 136-139; Goodman 2006, 173-179.)

Edelleen yksi kollektiivisen trauman käsittelytapa ovat olleet julkiset rituaalit. Ehkä tunnetuimpana mainitaan usein liittokansleri Willy Brandtin polvistuminen Varsovassa 1970. Vieraillessaan Varsovan geton kapinan uhrien muistomerkillä Brandt polvistui spontaanisti ja kunnioitti heidän muistoaan muutaman minuutin hiljaisuudella. (Giesen 2004a, 134; Brauer 2006.) Myös julkiset muistotilaisuudet, muistomerkit, 
museot ja näyttelyt ovat julkisen muistamisen keinoja. Moniin prosesseihin on liittynyt tapahtumapaikkojen selvittäminen ja merkitseminen muistomerkeillä. Esimerkiksi Saksassa tämä prosessi on kestänyt koko toisen maailmansodan jälkeisen ajan. (Giesen 2004a, 140-141.)

Edelleen monissa prosesseissa, esimerkiksi Pohjois-Irlannissa ja Etelä-Afrikassa (Ericson 2001) on pyritty erityisesti julkiseen tarinoiden jakamiseen. Monilla tahoilla on käynnistynyt prosesseja, joiden tarkoituksena on ollut purkaa vihollisidentiteettejä saattamalla molemmat osapuolet keskusteluyhteyteen. Kuten Alazar Barkan kuvaa:

Syyllisten ja uhrien välisestä vuorovaikutuksesta on tullut uusi poliittisen neuvottelun muoto, joka tekee mahdolliseksi historiallisen muistin ja identiteettien kirjoittamisen uudelleen tavoilla, jotka molemmat voivat jakaa. (Barkan 2000, xviii.)

Eri näkökulmat ja kokemukset tuodaan yhteen pöytään ilman, että täytyy päättää, kumpi osapuolista on oikeassa. Prosesseissa on myös korostettu vastuuta rauhasta; sotaa ja väkivaltaa on pidetty sotaosapuolien yhteisenä ongelmana

Kuten edellä olevat esimerkit osoittavat, julkisuudella on ollut monia rooleja kulttuuristen traumojen purkamisessa ja menneisyydenhallinnan prosesseissa. Seuraavassa tarkastelen Suomen 1918 tapahtumien muistelua vuonna 2008 tästä näkökulmasta. Millaisia rooleja julkisuudelle muisteluissa annettiin, ja miten julkisuus toimii tavoilla, jotka voisi ymmärtää kulttuurisen trauman purkamisena?

\section{Suomi 1918: kulttuurinen trauma?}

Suomen vuoden 1918 tapahtumat ovat monin tavoin tyypillinen esimerkki tapahtumasta, joka voidaan ymmärtää kollektiiviseksi traumaksi. Ennen muuta voittajan näkökulma hallitsi pitkään julkisessa elämässä ja häviäjien kokemukset painettiin pois virallisesta traditiosta (Peltonen 2003a; 2003b, 192).

Ulla-Maija Peltonen (2003b, 193-194) kuvaa, kuinka sodan muistelu jakautui kahtia valkoisten viralliseen tarinaan ja toisaalta sen vastapainoksi hävinneiden kertomuksiin kuolemista, sekasorrosta ja hautapaikoista. Sodan muistosta tuli poliittisen kamppailun kohde. Voittajat pystyttivät muistomerkkejä, kun taas hävinneiden muistomerkkejä kiellettiin pystyttämästä tai tuhottiin. Punaisten puolella kehittyivät tarinat, joissa vääryyksien toimeenpanijat saivat rangaistuksensa: pappi sairastui tai teki itsemurhan, teloittaja alkoholisoitui, sokeutui tai tuli mielisairaaksi. Yksi kamppailun kohde oli myös Mannerheim, joka oli valkoisille sankari, mutta punaisille roisto. (Peltonen 2003b, 193-198.)

1960-luvulla perinnearkistoihin kerättiin molempien osapuolien omakohtaisia kokemuksia sisällissodasta ja sen seurauksista. Näissä muisteluissa nousivat selvästi esiin erityisesti punaisten ja hävinneiden muistot, joita ei julkisesti juuri käsitelty. Nämä muistelut koskivat ennen muuta sodan terroria, väkivaltaa ja kuolemia, joista kerrottiin muistitietona. Esimerkiksi teloitettujen punaisten hautapaikat olivat arka ja virallisesti usein vaiettu asia.

Sota tulkittiin osapuolesta riippuen itsenäisyys- ja vapaustaisteluksi tai luokkataisteluksi. Myös sotaa esittävät kuvat jakautuivat kahtia. Muistojuhlissa ja lehdissä virallinen kansalaissotakuvasto esitti valkoisten näkökulmaa: sotatapahtumia, sotilaita ja 
päälliköitä, paraateja ja punavankeja. Epävirallinen hävinneiden kuvasto taas esitti sotatapahtumien lisäksi joukkokokouksia ja kotitarkastuksia, piilossa olevia hauta- ja teloituspaikkoja ja ruumisröykkiöitä (Peltonen 2003b, 135-136).

Vasta Väinö Linnan Täällä Pohjan tähden alla, joka ilmestyi 1960, nosti ensimmäisen kerran hävinneiden näkökulman esiin kansallisessa julkisuudessa. Ja vasta 200o-luvulla sotaa on pyritty muistelemaan niin, että siitä pystyttäisiin muodostamaan kokonaiskuva, johon mahtuvat molempien puolien muistot. Tässä mielessä merkittävin ponnistus oli projekti, jossa yritettiin selvittää jokaisen Suomessa vuosina 1914-1922 surmansa saaneen henkilöllisyys (Suomen sotasurmat 2004; Hentilä 2005).

Nykyisin yhä enemmän on kyse eri asioista: voittajien ymmärtäjät korostavat sodan lopputulosta, nousua neuvostonaapurin vallan alta. Hävinneiden ymmärtäjät korostavat sodan kärsimyksiä ja voittajien väkivallan laajuutta. Risto Alapuron mukaan oleellista on se, että nämä kaksi tulkintaa eivät ole toisiaan poissulkevia: kumpikin tulkinta voi jatkaa elämäänsä jopa yhden ja saman ihmisen mielessä. (Alapuro 2008, 13.)

Samanlainen tavoite, sodan kokonaiskuvan välittäminen, oli selvästi tavoitteena myös Tampereella vuonna 2008 järjestetyissä muisteluissa. Kuten museonjohtaja Toimi Jaatinen kuvasi Vapriikin Tampere 1918 -näyttelyn tavoitetta:

Tampereella tämä merkitsee tämän historian vaikeimman, mieltä kaihertaneen ja siksi mieluummin vaietun, ajanjakson muuttumista kaupunkilaisille tutuksi, yhteiseksi, jopa yhdistäväksi muistoksi (Tampere 1918 2008, 4).

Seuraavassa tarkastelen erityisesti niitä eri tapoja, joilla Tampereella vuotta 1918 muisteltiin julkisuudessa. Näitä tapoja ovat i) näyttelyn rakentaminen, ii) muistojen, eli valokuvien, dokumenttifilmien ja muistelujen kerääminen, iii) vuorovaikutteisuus: vieraskirjat, verkkomedia, blogit ja keskustelutilaisuudet, iv) osallistava draama ja pysäytetyt kuvat, sekä v) mediajulkisuus. Kuvaamalla näitä eri tapoja pohdin samalla, miten niiden luoma julkisuus toimi kollektiivisen trauman työstäjänä.

\section{Tampere 1918 -näyttely}

Tampereen vuoden 1918 tapahtumat olivat olleet paikkakunnalla kipeä, hankala ja pitkään vaiettu asia. Vuotta 1918 oli käytetty poliittisena lyömäaseena, ja edelleen eli pelko syyllistämisestä ja haavojen avaamisesta, koska se oli kipeä asia monien sukujen ja perheiden historiassa.

Hämeen museossa, josta sittemmin tuli Museokeskus Vapriikki, käytiin keskusteluja vuoden 1918 tapahtumia käsittelevästä näyttelystä heti sodan jälkeen. Vuonna 1918 Hämeen museon museonhoitaja Gabriel Engberg keräsi taistelupaikoilta ja sotasaalisvarastoista esineistöä, joka piti asettaa esille sodan jälkeen. Suunnitelma ei toteutunut. 1920-luvulla aihetta ei pidetty sopivana ja toisen maailmansodan jälkeen aihe tuntui hankalalta. Asiaa vaikeuttivat myös kunnallispolitiikan asetelmat. Tampereella hallitsi kokoomuksen ja sosialidemokraattien "aseveliakseli", jolle vuoden 1918 tapahtumat olivat hankalasti käsiteltäviä. 
1990-luvulla muisteleminen alkoi kuitenkin vähitellen avautua. Tärkeä keskustelun avaaja oli Heikki Ylikankaan Tie Tampereelle (1993), jossa Ylikangas kävi läpi Tampereen taisteluja. Kirjan pohjalta tehtiin myös näytelmä Tampereen Työväen Teatteriin (Ylikangas 1996). Vuonna 1998, sodan muiston 80-vuotispäivänä, pohdittiin yhteisen juhlan järjestämistä, mutta siihen ei vielä silloin kyetty ja hanke raukesi (Malmi 2009).

2000-luvulla kunnallispolitiikassa aseveliakseli murtui, kun vihreät nousivat kaupunginhallitukseen kokoomuksen kanssa. Politiikassa ja myös museoissa ja yliopistolla alkoi nousta uusi sukupolvi, jonka yhteys vuoden 1918 tapahtumiin oli kahden sukupolven takainen. Suurilla ikäluokilla vuosi 1918 oli vielä hyvässä muistissa, koska heidän vanhempansa olivat olleet mukana sotatapahtumissa.

Museokeskus Vapriikissa syntyi ajatus näyttelyn kokoamisesta vuodeksi 2008, kun sodasta olisi kulunut 90 vuotta. Näyttelyn työryhmässä oli mukana museon projektijohtaja Kimmo Antila ja yliopiston historian tutkijoita. Tavoitteena oli kuvata sotaa monipuolisesti. Erityisesti haluttiin välttää poliittista leimautumista häviäjien tai voittajien näyttelyksi. (Antila 2009; Jaatinen 2008, 5.)

Tavoitteena oli myös tuottaa kokemus siitä, miltä sota tuntui tavallisen ihmisen tasolla. Antilan (2009) mukaan perusajatus oli asettaa katsoja vuoden 1918 tapahtumien keskelle ja kysyä, mitä itse kukin olisi itse tehnyt samassa tilanteessa.

Näyttely rakennettiin matkaksi sodan halki. Se alkoi sodan lähtökohtien erittelyllä: näyttelyssä käytiin läpi Tampereen elinoloja vuosisadan vaihteessa ja kuvattiin ihmisten arkea ja kotioloja. Sen jälkeen kuvattiin taistelujen etenemistä ja kulkua niin, että katsoja saattoi kävellä tapahtumien keskellä taistelun äänien ja musiikin keskellä.

Näyttelyssä oli esillä sodan esineistöä: aseita, lippuja, astioita ja vaatteita. Näistä moniin liittyi erityistä dramatiikkaa. Esillä oli esimerkiksi kuva jääkäristä kahvipöydässä ennen taisteluja, ja sitten hänen univormunsa, jossa oli kuolemaan johtaneen luodin reikä niskassa. Tai esillä olivat punaisten vankilana toimineen Aaltosen kenkätehtaan nahkavaraston hyllyt, joihin vangit olivat kirjoittaneet muistokirjoituksiaan. Katsoja sai mennä myös kuulusteluhuoneeseen, jossa saattoi asettua kuulusteltavaksi, kun nauhalta luettiin kysymyksiä. Toisessa osiossa katsoja joutui teloitusryhmän kivär̈rinpiippujen eteen.

Näyttelyssä kuvattiin myös väkivaltaa ja kuolleita. Mukana oli kuvia kaatuneista kaupungin kaduilta ja lavastuksia vainajista. Lisäksi kerrottiin lapsisotilaista, esimerkiksi 13- ja 14-vuotiaista pojista, joista toinen taisteli valkoisten ja toinen punaisten puolella. Heistä toinen kuoli saamiinsa vammoihin ja toinen teloitettiin.

Kulkemalla näyttelyn halki katsoja pyrittiin asettamaan silminnäkijäksi ja kokijaksi, joka tunsi itse kummankin osapuolen ja sodassa olleiden ihmisten kokemukset. Tarkoituksena ei ollut selittää sodan syitä, vaan enemmänkin kuvata ja näyttää sitä, mitä oli tapahtunut ja antaa vierailijoille itselleen tilaisuus päättää, mitä ajatella. 


\section{Sodan muistot: valokuvat, dokumenttifilmit ja muistelut}

Yksi julkisen työstämisen tärkeä elementti oli vuoden 1918 tapahtumiin liittyvien muistojen ja dokumenttien systemaattinen kerääminen ja esittely tavalla, jolla vuoden 1918 kuvaa voitiin rikastaa.

Vapriikin oman esineistön lisäksi näyttelyyn hankittiin runsaasti muuta materiaalia. Näyttelyyn etsittiin valokuvia ja filmimateriaalia julkisista ja yksityisistä kokoelmista ja perhealbumeista. Prosessin aikana löytyi uusia kuvia ja vanhoja kontekstualisoitiin, eli niiden tarinaa ja ottotilannetta selvitettiin.

Näyttelyissä oli myös esillä dokumentaarista kuvamateriaalia, joka hajotti stereotyyppisiä käsitystä selvistä voittajista ja häviäjistä. Näyttelyssä oli esimerkiksi nostettu näkyvästi esiin potretit, joita sekä punaiset että valkoiset otattivat itsestään kuvaamoissa. Ne nostivat esiin sen idealistisen innoituksen, jonka varassa taisteluihin lähdettiin puolin ja toisin. Sotaan lähtijöiden kasvoilla näkyi tulevaisuudenusko ja optimismi: sota näytti tarjoavan lupauksen paremmasta maailmasta.

Kuvissa näytettiin myös katunäkymiä, joista välittyi sekasortoinen ja sekava todellisuus: kaduilla viruneita kuolleita, tuhoutunutta kaupunkia, vankeja ja siviilejä. Näiden vastapainona olivat otokset paraateista ja sotaharjoituksista, jotka esittivät sodan juhlallista puolta ja sitä, kuinka voittajat kävivät omaa symbolista taisteluaan.

Suomen elokuva-arkistosta saadut filmit näyttivät valkoisten taisteluharjoituksia Pohjanmaalla, saksalaisten joukkojen etenemistä junalla ja heidän joutumistaan punaisten väijytykseen, sekä punaisten puolelta heidän johtajiansa.

Lisäksi etsittiin muistelijoita ja silminnäkijöitä: eri-ikäisiä inmisiä, jotka kertoivat omia ja suvussa kulkeneita muistojaan sodasta. Näitä muisteluita kuvattiin ja ne pyörivät näyttelyssä. Tunnetuimpana hahmona oli jo iäkäs Kauko Lindell, joka oli yhdessä näyttelyn valokuvassa pienenä 10-vuotiaana poikana. Lindellistä tuli vuoden 2008 muistelujen symbolinen hahmo, jonka kirkkaita ja tarkkoja muistikuvia esitettiin sekä näyttelyssä että mediassa.

Muistelmiaan esittivät myös nuoremmat ihmiset. Esimerkiksi tunnettu muusikko Jaakko Löytty kertoi perheestään, jossa oli ollut sekä punaisia että valkoisia, ja niistä tavoista, joilla tämä kahtiajako oli vaikuttanut suvun elämään.

\section{Vuorovaikutteisuus: luennot, verkkomedia ja sovinnon kirja}

Näyttelyn oheen rakennettiin myös vuorovaikutteisia tapahtumia ja tiloja, joissa asiasta kiinnostuneet saattoivat itse tuoda ajatuksiaan esiin. Vapriikki järjesti näyttelyn yhteyteen keskustelutilaisuuksia ja luentoja, joissa sodan muistoa käytiin läpi ja siitä keskusteltiin. Näyttelyn suunnittelussa mukana olleet historiantutkijat toivat esiin historiantutkimuksen näkökulmia Tampereen tapahtumiin. Heidän panoksensa oli merkittävä näyttelykirjan kokoamisessa. Näyttelystä julkaistiin myös Tampereen museoiden julkaisusarjassa 300-sivuinen kuvitettu kirja, Tampere 1918 (2008), joka oli Tieto-Finlandia-kilpailun ehdokkaana.

Vapriikin verkkosivuilla toimi lisäksi blogeina palaute- ja keskustelufoorumi, jossa ihmiset saattoivat kertoa omia kokemuksiaan ja keskustella niistä. Näyttelyn lopussa oli myös vieraskirja, johon näyttelyn vierailijat alkoivat kirjoittaa omia aja- 
tuksiaan ja kokemuksiaan niin, että kirjasta tuli "sovinnon kirja", jossa moni kuittasi vuoden 1918 tapahtumat käsitellyiksi.

\section{Julkinen katudraama: Sovinnon päivä ja kapinaraitti}

Tampereen tapahtumia käsiteltiin myös erityisesti katudraaman keinoin. Tampereella järjestettiin huhtikuun 6. päivänä 2008 Sovinnon päivä, johon kuului Haavoittunut enkeli -katusaatto sekä pysäytettyjen kohtausten varaan rakennettu Päivä Tampereella 1918 -kuvaelma (Päivä Tampereella 2008). Tampereen kaupungin kulttuuritoimi oli myös mukana rakentamassa erityistä "kapinaraittia"², kävelyreittiä, joka kulki taistelupaikkojen lävitse.

Historiantutkija, kirjailija ja Tampereen yliopiston tiedotuspäällikkö Timo Malmi oli tutustunut pysäytettyjen kuvien, tableaux vivants -tyylillä esitettyyn katudraamaan Unkarin vuoden 1956 kansannoususta. Malmi teki käsikirjoituksen ja kokosi paikallisista voimista yhteenliittymän, joka toteutti samalla tekniikalla Sovinnon päivän. Työn pohjana oli myös Malmin ja Ari Järvelän kirja, johon he keräsivät suoria sotakokemuksia ja - muistoja tutkimuksesta, kirjallisuudesta ja arkistoista (Malmi \& Järvelä 2008). Tapahtumasta kasvoi julkinen katudraama, jonka järjestäjinä olivat Tampereen yliopiston alumnit, Teatteri Siperia sekä Finlaysonin perinnetoimikunta. Lisäksi otettiin yhteyttä erilaisiin paikallisiin järjestöihin ja poliittisiin paikallisjärjestöihin ja pyydettiin heiltä halukkaita mukaan näyttelijöiksi. Tavoitteina oli muistella aikakauden ihmisiä ja tapahtumia ja ymmärtää edellisten sukupolvien toimintaa vaikeissa tilanteissa (Päivä Tampereella 2008, 4; Malmi \& Järvelä 2008).

Malmi (2009) kuvasi tapahtuman tavoitteita niin, että tarkoituksena oli käsitellä kiellettyä aihetta ja kuvata Tampereen taistelua, joka oli Madridin, Varsovan, Berliinin, Leningradin ja Stalingradin taisteluiden kaltainen suuri kaupunkitaistelu, ja jossa oli suomalaisten lisäksi mukana venäläisiä, ruotsalaisia, saksalaisia ja juutalaisia. Tärkeänä tavoitteena oli näin säilyttää kaikkien kunnia ja tuoda esiin sitä, kuinka taisteluun lähdettiin molemmin puolin hyvän asian puolesta: vapauden tai paremman tulevaisuuden toivossa.

Sovinnon päivä jakautui kahteen osaan: kaupungin halki kulkeneeseen Haavoittunut enkeli -saattoon ja teatteri Siperian dramatisoimiin pysäytettyihin kuviin. Haavoittunut enkeli oli historiallinen kulkue, johon osallistui noin 100 ihmistä roolihahmoissa ja joka kulki kaupungin keskustan halki tuomiokirkolta Finlaysonin tehtaan alueelle. Kulkueessa olivat kaikki sodan osapuolet: valkoiset, punaiset, venäläiset, saksalaiset, Punainen Risti ynnä muut. Kaikilla osallistujilla oli nimi, ja tunnetut tamperelaiset esittivät kukin jotakin nimettyä henkilöä. Mukana oli molempien puolien johtajia ja taistelijoita sekä sovittelijoita ja lääkintähenkilökuntaa.

Malmin (2009) mukaan ideana oli, että ihmiset esittäisivät henkilöä, joka olisi "vastapuolelta", eli edustaisi tahoa, johon he itse eivät voisi ajatella nykytilanteessa samastuvansa. Kulkueesta teetettiin myös esittelylehtinen, jossa tärkeimmät roolihenkilöt oli kuvattu ajan mukaisissa asuissa ja esitelty lyhyesti.

Kulkueen kärjessä kuljetettiin haavoittunutta enkeliä, Tampereen "suojeluspyhimystä", joka oli konstruoitu Hugo Simbergin tunnetun maalauksen mukaisesti. Kulkueen kärjessä kulkivat sekä punaisten että valkoisten soittokunnat ja mukana oli myös kuoro. Tunnelma oli harras ja liikuttunut. Tapahtumassa oli yleisöä tuhansia 
inmisiä, Tampereen kadut olivat tungokseen asti täynnä väkeä, joka seurasi ensin kulkuetta ja sen jälkeen vaelsi Finlaysonin alueella katsomassa pysäytettyjä kuvia.

Päivä Tampereella -kuvaelma oli puolestaan sarja pysäytettyinä kuvina esitettyjä kohtauksia, jotka Teatteri Siperia oli dramatisoinut Finlaysonin tehtaiden alueelle. Kun kulkue saapui tehtaan alueelle, sen perässä kulkenut yleisö saattoi kulkea tehtaan alueella ja katsella kohtauksia, joissa dramatisoitiin vuoden 1918 tapahtumia.

Lisäksi Tampereelle rakennettiin myös ns. "kapinaraitti" (Kapinaraitti 2009), historiallinen kävelyreitti, jolla saattoi tutustua vuoden 1918 tapahtumiin liittyviin paikkoihin ja rakennuksiin. Raitti liitettiin Tampereen kaupungin kulttuuriraitteihin, joita kaupungin kulttuuripalvelut on rakentanut kaupunkiin ${ }^{3}$. Reitillä järjestettiin opastettuja kävelyjä ja siitä tehtiin esite.

\section{Mediajulkisuus: lehdistö ja sähköiset välineet}

Vuoden 1918 tapahtumia käsiteltiin myös medioissa runsaasti. Näyttelyistä ja Sovinnon päivästä julkaistiin lehtiartikkeleita ja aihetta käsiteltiin sähköisissä välineissä. Vapriikin näyttelyn lehdistöseurannassa on tyypillisenä juttuna näyttelyä ja sen näkökohtia lyhyesti esittelevä juttu, ja poikkeuksetta sävy oli hyvin myönteinen. Erityisesti paikallinen Aamulehti sekä TV2:n Ajankohtainen Kakkonen uutisoivat sekä näyttelyn että Sovinnon päivän tapahtumat näyttävästi ja olivat mukana tuottamassa yhteistä julkisuutta.

Tampereella toimiva TV2 järjesti myös erityisen keskusteluillan vuoden 1918 tapahtumista. Ohjelmassa toistettiin sodan "alkuperäiset" asetelmat eli keskustelijat edustivat vastakkaisia puolia ja keskustelun sävy oli ajoittain kiivas, kun eri osapuolet ottivat yhteen. Ohjelma poikkesikin median valtavirrasta kärjistäessään ja toistaessaan vanhoja vastakohtaisuuksia (Antila 2009; Malmi 2009).

\section{Trauman työstäminen: identiteettien uudelleenajattelu}

Miten edellä kuvatut vuoden 1918 julkiset muistelut voi ymmärtää kollektiivisen tai kulttuurisen trauman purkamisena? Sisällissodan logiikkaan kuuluu usein ehdottomuus: omia ja vieraita erottaa ylittämätön juopa. Ryhmittymät, jotka ovat eläneet pitkään lähekkäin alkavat nähdä toisensa pahimpina vihollisinaan. (Appadurai 2006, 51.) Tätä ilmiötä on tarjottu selitykseksi läheisten ryhmien välillä leimahtavaan vihaan niin myös Suomen sisällissotaan (Alapuro 2008).

Tämä voi olla yksi narsismin muoto: tarvetta luoda itsestä kaikkivoipainen fantasia. Väkivallan lopettamisen ehtona on sekä itseä että toisia koskevien fantasioiden murentaminen. Jos emme vaadi itseltämme kaikkivoipaisuutta, voimme sietää myös toisia vähän paremmin (Ignatieff 1999, 62).

Tampereen näyttelyissä, kulkueessa ja katudraamoissa oli tavoitteena keskinäisen vihanpidon lopettaminen ja ryhmäfantasioiden purkaminen. Tilalle nostettiin sodan todellisuus sekavuuksineen, sotkuisuuksineen ja paradokseineen. Taistelevilla oli myös paljon yhteistä kuten ihanteellisuus ja traagiset kohtalot. Voittajilla oli apunaan saksalaiset joukot, ja punaiset lähtivät sotaan voitontahtoa uhkuen. Sodassa oli myös sivustakatsojia, lapsia ja muita sivullisia, jotka jäivät taistelevien joukkojen jalkoihin. 
Tampereen muistelujen perusteella voi myös sanoa, että trauman julkisen purkamisen suurin arvo on ehkä niille, joiden henkilöhistoriaa sota on konkreettisesti koskettanut. Muisteleminen tarjoaa keinon tuoda esiin omat kokemukset ja verrata niitä toisten kokemuksiin. Tieto menneisyydestä ja sen eri puolista voi avata uusia näkökulmia omaan perhe- ja henkilöhistoriaan.

Voi myös ajatella, että muistelemisella on arvonsa niille, joita sota on koskettanut siirtotaakkana: voittona tai häviönä, joka on velvoittanut tulevia sukupolvia joko syyllisiksi tai uhreiksi. Menneisyyden epäoikeudenmukaisuudet voivat siirtyä eteenpäin sekä uhriuden että väärintekijän identiteetteinä. Voittajien puolella on tyypillistä myös kantaa syyllisyyttä aiempien sukupolvien teoista. Hävinneiden puolella ongelmana on uhriuden identiteetti, joka periytyy ja sälytetään seuraavien sukupolvien kannettavaksi (Mbembe 2008,7 ) melankoliana ja voimattomuutena. Tästä on puhuttu erityisesti esimerkiksi mustien (Luciano 2000) ja vasemmiston melankoliana (Scribner 2000; Brown 2000). Suomessa Anu Koivunen (2006) on jäljittänyt kiinnostavalla tavalla työväenluokan miehistä melankoliaa Aki Kaurismäen elokuvasta Mies vailla menneisyyttä.

Tampereen muistelut saattavatkin toimia siirtotaakkoja purkavasti, koska ne ovat rohkaisseet sodan kokemusten ilmaisemiseen ja samalla pyrkineet näkemään sisällissodan omana historiallisena hetkenään, joka ei enää velvoita nykyhetken sukupolvia. Ajatuksena on, että jos suhde menneisyyteen muuttuu avoimemmaksi ja joustavammaksi, myös nykyisyyteen voi suhtautua joustavammin.

\section{Tampereen julkisuus: trauman purkamista?}

Miten sitten julkisuus toimi kollektiivisen trauman purkajana Tampereen tapauksessa? Vuoden 1918 muistelu osoittaa, että välineet julkisessa muistelussa ja trauman työstämisessä voivat olla hyvin moninaisia. Tampereen muistelut näyttivät sen moninaisuuden ja kirjon, jota julkinen trauman purkaminen voi merkitä.

Perinteinen "valtamedia", lehdistö ja televisio, oli lopulta sivuroolissa. Kyseessä eivät ole vain palstamillimetrit valtakunnan päälehtien etusivuilla tai iltauutisissa, vaan Tampere 1918 -tapahtuman ympärille rakentui huomattavasti monisyisempi julkinen muisteluprosessi. Nimenomaan kollektiivisen trauman purkamisen näkökulmasta olivat tärkeitä museon näyttely esineistöineen ja kuvamateriaaleineen, tallennetut muistelot, dramatisointi, katukulkue ja pysäytetyt kuvat, järjestöt ja julkiset instituutiot, keskustelutilaisuudet, vieraskirja sekä näyttelyssä että verkossa sekä blogit.

Purkaminen noudatteli ennen kaikkea tarinoiden jakamisen (Ericson 2001, Barkan 2000, xviii) ideaa: näyttelyissä ja katudraamassa pyrittiin selvästi kokonaiskuvaan, jossa eri tarinat saavat elää, mutta ne voidaan nähdä saman ison tulkinnan eri puolina. Erityisen tärkeää olikin mahdollisuus julkiseen vuorovaikutteisuuteen. Tampereella kerättiin ja esitettiin aktiivisesti muistoja ja muisteluja, ja myös rohkaistiin yleisöä tuomaan esiin omia muistojaan ja kommenttejaan ja keskustelemaan niistä keskustelutilaisuuksissa tai verkossa.

Myös verkko on tuonut uusia tapoja, joiden kautta ihmiset voivat tuoda esiin muistojaan ja keskustella niistä. Verkko ei katoa niin nopeasti kuin perinteisempi journalismi ja pitää yllä keskusteluareenaa pidemmällä aikajaksolla. Verkon kautta monet voivat saada äänensä kuuluviin, purkaa tuntojaan ja tutustua myös toisten ajatuksiin. 
Julkisissa esityksissä sekä dokumentaarisuudella että draamalla oli kummallakin oma erityinen roolinsa. Trauman purkamiseen liittyy oleellisesti eläytyminen menneeseen historialliseen tilanteeseen, ei ainoastaan tiedon välittäminen ja keskustelu. Julkinen draama - sodan dramatisointi näyttelyssä, katudraamassa tai jopa itse näyttelemällä - oli tärkeässä roolissa sodan todellisuuden välittämisessä. Dokumentit - sodasta kerätty esineistä ja omakohtaiset muistelot - välittivät sodan kokemusta konkreettisesti.

Muisteluiden julkisuus haastaa myös valtajournalismin. Journalismi etsii usein selkeitä syyllisiä ja uhreja ja kärjistää ristiriitoja. Tämä logiikka nousi esiin esimerkiksi ns. Muhammed-sarjakuvien herättämässä julkisessa kohussa, jossa ongelma paisui keskusteluksi kuvitellusta sivilisaatioiden törmäyksestä läntisen sananvapauden nimissä (Kunelius \& Eide 2007; Eide ym. 2008) ja mediat olivat prosessissa mukana. Joskus journalismi myös syyllistyy voyerismiin (Yaeger 2002) tirkistellessään kärsimystä ja kuolemaa muuttaen ne mielihyvää tuovaksi viihteeksi.

Trauman purkamisen näkökulmasta julkisuuden tarkoituksena on neuvottelu ja vuorovaikutus: vihollisten tuominen saman pöydän ääreen ja asioista keskusteleminen (Barkan 2000, 321). Tästä näkökulmasta julkisuudessa pitäisi pyrkiä esittämään myös traumaattisiin tapahtumiin liittyvää ristiriitaisuutta ja sekavuutta. Journalismin tehtävänä voisikin olla vihollisuuksien kärjistämisen ja yksinkertaistamisen sijaan kanavan tarjoaminen myös niille, joilla ei ole selvää vihollista tai syyllistä tiedossa eikä valmiita vastauksia siihen, mitä vastaan pitäisi seuraavaksi lähteä.

\section{Trauman purkamisen rajat}

Kollektiivisen trauman purkamisella on kuitenkin myös rajansa. Se voi toimia vallitsevan järjestyksen ja menneisyyden vääryyksien oikeuttajana. Esimerkiksi apartheidin seuraukset ovat edelleen vakavia ja kriitikot ovat syyttäneet totuuskomissiota käsienpesuoperaatioksi, jossa sekä valkoinen että musta eliitti ovat hyötyneet (Mbembe 2008) eivätkä tunnustukset ole tuottaneet kollektiivista tunnetta sovinnosta ja anteeksiannosta (Posel 2008). Tämä ristiriitaisuus on läsnä kaikissa muisteluprosesseissa. Toisaalta on tarve käydä oikeutta: löytää totuudet, uhrit ja syylliset. Toisaalta on tarve päästä eroon stereotyyppisistä viholliskuvista, joiden varassa trauma vaikuttaa.

Tämä jännite oli läsnä myös Tampereen 1918 tapahtumien muistelussa ja oli vaikuttamassa siihen, että julkista muistelua oli vaikea järjestää aikaisemmin. Näyttelyiden ja katudraaman järjestäjät (Antila 2009; Malmi 2009) pyrkivät vastaamaan tähän jännitteeseen niin, että tarkoituksena ei ollut ottaa kantaa puolesta eikä vastaan, vaan kertoa tapahtumien moninaisuudesta ja jättää tapahtumiin osallistuneille mahdollisuus muodostaa itse omat mielipiteensä. On kuitenkin selvä, että trauman purkaminen ei voi korvata historiantutkimusta tai oikeudenkäyntiä, joilla on edelleen omat roolinsa.

Tampereen muistelut osoittavat myös, että kollektiivisen trauman purkaminen vaatii aikaa. Erityisesti vuoden 1989 jälkeen monet valtiot ovat heikentyneet ja niissä on kärsitty valtion sisäisestä väkivallasta: sisällissodista, kansanmurhista ja terrorismista (Appadurai 2006, 103). Suomen sisällissota 1918 muistuttaa näitä kriisejä siinä, että se oli valtion sisäinen sota, joka syttyi valtatyhjiössä toisiaan hyvin tuntevien 
ihmisten välillä. Venäjän vallankumouksen myötä tsaarin valta murtui ja Suomessa syntyi taistelu siitä, kuka saa johtaa valtiota.

Tampereen esimerkki osoittaa, että trauman julkisessa työstämisessä yksi avaintekijä on aika. Esimerkiksi Ignatieff (1999) arvelee, että Balkanilla muisteleminen on vielä liian aikaista sodille: kylissä naapurukset tappoivat toisiaan 1990-luvulla. Tampereellakin yhteisen trauman työstäminen oli mahdollista vasta, kun sodassa olleiden lastenlapset ryhtyivät sitä tekemään.

Toisaalta trauman työstämistä ei pitäisi myöskään täysin tyrmätä. Ehkä odotukset pitää vain asettaa vaatimattomammin. Trauman työstämiselle on paikkansa silloin, kun sille ei ole ylitsepääsemättömiä esteitä. Se voi auttaa rakentamaan positiivisempia kollektiivisia ja yksilöllisiä identiteettejä. Joissakin tapauksissa se voi myös estää väkivallan toistumista ja koston kierteitä. Se voi olla myös yksittäisille ihmisille keino tulla toimeen menneisyytensä kanssa ja auttaa heitä jatkamaan elämäänsä entistä vapaampina.

Mutta samalla on pidettävä mielessä, että trauman työstämiseen liittyy aina politiikkansa: se on vain yksi yritys helpottaa inmisten elämää menneisyytensä kanssa ja silloinkin on oltava tarkkana, kenen elämää helpotetaan ja millä tavalla.

\section{Viitteet}

1 Tampere 1918. Museokeskus Vapriikki, Tampere, alkaen 24.4.2008. http://vapriikki.net/ tampere1918/

2 Kapinaraitti. Tampereen kaupungin kulttuuripalvelujen esite. Saatavilla: http://www.tampere.fi/ tiedostot/5xPxZusKd/Kapina_raitti_netti.pdf.

3 Kulttuuriraitit. Tampereen kaupungin kulttuuriraittien verkkosivut. Saatavilla: http://www. tampere.fi/kulttuuri/palvelut/raitit/index.html\#CONTENT.otsikko.29.

\section{Haastattelut}

Antila, Kimmo (2009). Kimmo Antila, projektijohtaja, Museokeskus Vapriikki, 9.2.20o9.

Malmi, Timo (2009). Timo Malmi, Päivä Tampereella 1918, käsikirjoittaja ja ohjaaja, 9.2.20o9.

\section{Kirjallisuus}

Adelaid-Tart, Aili (2006). Cultural trauma and life stories. The Aleksanteri Insititute, Kikimora Publications A 15.

Alapuro, Risto (2008). Sisällissodan väkivallan kuvia. Teoksessa Kukkonen, Jukka \& Heikka, Elina (toim.) Punamustavalkea - 1918 kuvat. Suomen valokuvataiteen museon julkaisuja 24, 11-22.

Alexander, Jeffrey (2006). The civil sphere. Oxford: Oxford University Press.

Alexander, Jeffrey (2004). Toward a theory of cultural trauma. Teoksessa Alexander, Jeffrey; Eyerman, Ron; Giesen, Bernhard; Smelser Neil \& Sztompka, Piotr: Cultural trauma and collective identity. Berkeley: University of California Press, 1-30.

Alexander, Jeffrey (2003). The meanings of social life: A cultural sociology. Oxford: Oxford University Press.

Alexander, Jeffrey; Giesen, Bernhard \& Mast, Jason (toim.) (2006). Social performance: Symbolic action, cultural pragmatics and ritual. Cambridge: Cambridge University Press.

Alexander, Jeffrey; Eyerman, Ron; Giesen, Bernhard; Smelser Neil \& Sztompka, Piotr (2004). Cultural trauma and collective identity. Berkeley: University of California Press. 
Appadurai, Arjun (2006). Fear of small numbers: An essay on the geography of anger. Durham: Duke University Press.

Attwood, Bain, Chakraparty Dipesh \& Lomnitz, Claudio (2008). The public life of history. Public Culture 20: 1, 1-4.

Barkan, Elazar (2000). The guilt of nations: Restitution and negotiating historical injustices. New York: W.W. Norton.

Brauer, Valentin (2006). Symbols in action: Willy Brandt's kneefall at the Warsaw Memorial. Teoksessa Alexander, Jeffrey; Giesen, Bernhard \& Mast, Jason (toim.) Social performance: Symbolic action, cultural pragmatics and ritual. Cambridge: Cambridge University Press, 257-277.

Brown, Wendy (2000). Resisting left melancholia. Teoksessa Eng, David L. \& Kazanjan, David (toim.) Loss: The politics of mourning. Berkeley: University of California Press, 458-466.

Carey, Henry (toim.) (2003). National reconciliation in Eastern Europe. Boulder, East European Monographs, no 614.

Eide, Elisabeth, Kunelius, Risto \& Phillips, Angela (toim.) (2008). Transnational media events: The Mohammed cartoons and the imagined clash of civilizations. Göteborg: Nordicom.

Ericson, Maria (2001). Reconciliation and the search for a shared moral landscape: An exploration based upon a study of Northern Ireland and South Africa. Frankfurt am Main: P. Lang.

Eyerman, Ron (2001). Cultural trauma: Slavery and the formation of African American identity. Cambridge: Cambridge University Press.

Galtung, Johan \& Ruge, Mari (1965). The structure of foreign news: The presentation of the Congo, Cuba and Cyprus crises in four Norwegian newspapers. Journal of International Peace Research 2: 1, 64-91.

Giesen, Bernhard (2004a). Triumph and trauma. London: Paradigm Publishers.

Giesen, Bernhard (2004b). The trauma of perpetrators. Teoksessa Alexander, Jeffrey; Eyerman, Ron; Giesen, Bernhard; Smelser Neil \& Sztompka, Piotr. Cultural trauma and collective identity. Berkeley: University of California Press, 112-154.

Goodman, Tanya (2006). Performing a "new" nation: the role of the TRC in South Africa. Teoksessa Alexander, Jeffrey; Giesen, Bernhard \& Mast, Jason (toim.) Social Performance. Symbolic Action, Cultural Pragmatics and Ritual. Cambridge: Cambridge University Press, 169-192.

Hayner, Isabella (2002). Unspeakable truths: Facing the challenges of truth commissions. London: Routledge.

Hentilä, Seppo (2005). Löytyykö totuus komissioista? Historiantutkimus ja totuuskomissiot. Tieteessä tapahtuu 8/2005.

Hydén, Göran (2000). Post-war reconciliation and democratization: Concepts, goals and lessons learnt. Bergen: Chr. Michaelan institute.

Ignatieff, Michael (1999). The warrior's honor: Ethnic war and the modern conscience. London: Vintage.

Koivunen, Anu (2006). Do you remember Monrépos? Melancholia, modernity and working class masculinity in the Man without A Past (Aki Kaurismäki 2002). Teoksessa Thomsen, Claire (toim.) Northern constellations: New readings in Nordic cinema. London: Norvik Press, 133-148.

Kunelius, Risto \& Eide, Elisabeth (2007). The Mohammed cartoons, journalism, free speech and globalization. Teoksessa Kunelius, Risto; Eide, Elisabeth; Hahn, Oliver \& Schroeder, Roland (toim.) Reading the Mohammed cartoons controversy: An international analysis of press discourses on free speech and political spin. Working Papers in International Journalism/Arbeitshefte Internationaler Journalismus 2007/1. Bochum: Projektverlag, 9-23.

Luciano, Dana (2000). Passing shadows: Melancholic nationality and black critical publicity in Pauline E. Hopkins's Of One Blood. Teoksessa Eng, David L. \& Kazanjan, David (toim.) Loss: The politics of mourning. Berkeley: University of California Press, 148-187.

Malmi, Timo ja Järvelä, Ari (2008). Tampere tulessa. Jyväskylä: Atena.

Mbembe, Achille (2008). Passages to freedom: The politics of racial reconciliation in South Africa. Public Culture 20: 1, 5-18.

Moon, Claire (2008). Narrating political reconciliation: South Africa's truth and reconciliation commission. Lanham: Lexington Books.

Peltonen, Ulla-Maija (2003a). Muistin paikat: Vuoden 1918 sisällissodan muistamisesta ja unohtamisesta. Helsinki: SKS.

Peltonen, Ulla-Maija (2003b). Vuoden 1918 muistot. Teoksessa Kervanto Nevanlinna, Anja \& Kolbe, Laura (toim.) Suomen kulttuurihistoria 3. Helsinki: Tammi, 192-198.

Posel, Deborah (2008). History as confession: The case of South African truth and reconciliation comission. Public Culture 20: 1, 119-141. 
Päivä Tampereella 1918 (2008). Haavoittunut enkeli -saaton ja Päivä Tampereella 1918 -kuvaelman ohjelma. Tampere: Tampereen Yliopiston Alumni ry, Teatteri Siperia ja Finlaysonin perinnetoimikunta.

Rose, Jacqueline (1996). States of fantasy. Oxford: Clarendon Press.

Scribner, Charity (2000). Left melancholy. Teoksessa Eng, David L. \& Kazanjan, David (toim.) Loss: The politics of mourning. Berkeley: University of California Press, 300-322.

Sesay, Amadu (2007). Does one size fit all? The Sierra Leone truth and reconciliation commission revisited. Uppsala: Nordiska Afrikainstitutet.

Smelser, Neil (2004). Psychological trauma and cultural trauma. Teoksessa Alexander, Jeffrey; Eyerman, Ron; Giesen, Bernhard; Smelser Neil \& Sztompka, Piotr Cultural Trauma and Collective Identity. Berkeley: University of California Press, 31-59.

Stahn, Carsten (2001). Accommodating individual criminal responsibility and ntional reconciliation: The UN truth commission for East Timor. The American Journal of International Law 95: 4, 952966.

Suomen sotasurmat (2004). Vuosina 1914-22 sotaoloissa surmansa saaneiden nimitiedosto. Saatavilla:http://vesta.narc.fi/cgi-in/db2www/sotasurmaetusivu/main?lang=fi (luettu 15.1.2008).

Tampere 1918 (2008). Tampereen museoiden julkaisuja 100.

Taylor, Charles (1994). The politics of recognition. Teoksessa Gutman, Amy (toim.) Multiculturalism: Examining the politics of recognition. Princeton: Princeton University Press.

Teneboim-Weinblatt, Keren (2008). "We will get through this together": Journalism, trauma and the Israeli disengagement from the Gaza Strip. Media, Culture Q Society 30: 4, 495-513.

Torpey, John (toim.) (2003). Politics and the past: On repairing historical injustices. Lanham, MD: Rowman \& Littlefield.

Yaeger, Patricia (2002). Consuming trauma; or the pleasures of merely circulating. Teoksessa Miller Nancy K. \& Tougaw, Jason (toim.) Extremities: Trauma, testimony, and community, Urbana and Chicago: University of Illinois Press, 25-51.

Ylikangas, Heikki (1993). Tie Tampereelle: Dokumentoitu kuvaus Tampereen antautumiseen johtaneista sotatapahtumista Suomen sisällissodassa. Porvoo: WSOY.

Ylikangas, Heikki (1996). Tie Tampereelle. Heikki Ylikankaan teoksen pohjalta kirjoittaneet Ritva Holmberg ja Harri Virtanen. Tampere: Tampereen Työväen Teatteri. 